\title{
Is It Possible to Quantify the Roman Agrarian Economy? In Favour of Quantitative Scepticism
}

\author{
Javier Salido Domínguez
}

$\mathbf{1}$

Introduction

There has been a resurgence of interest in the analysis of Roman raised granaries and horrea in recent years. Since the publication of Rickman's reference work Roman Granaries and Store Buildings (1971), which started a golden decade in the study of Roman horrea, thanks to works by Manning (1975), Gentry (1976), Morris (1979), Petculescu (1987) and Gast \& Sigaut (Gast and Sigaut 1979; Gast, Sigaut, and Bruneton-Governatori 1981; Gast et al. 1985), much has been published on this type of structure and it is currently subject to analysis by different specialists and working groups.

Research has mainly focused on the study of construction techniques, that have allowed us to correctly identify the granaries from the archaeological point of view. The publication of different typologies, the explanation of the use of certain construction materials and the application of new techniques of excavation and archaeological analysis have significantly renewed our perception and interpretation of these structures. However, for many years specialists have run up against an intractable problem: how to measure the amount of grain kept inside the warehouses. Various attempts have been made to estimate the capacities of individual granaries, usually to see if the military horrea would hold sufficient grain for the garrison for one year or if the rural granaries would have sufficient capacity for storing the harvest. Unfortunately the question has not been solved yet and we will try here to address this subject from the archaeological point of view.

\section{Proposals about the Capacity of Roman Granaries}

In the earliest published works on Roman warehouses and granaries, we already find the specialists' preoccupation with solving one of the most difficult problems in the interpretation of the archaeological data: how to calculate the capacity of raised granaries. Manning $(1975,116)$ in his analysis of the Roman 
military timber granaries posited that grain was stored to a height of $1.5 \mathrm{~m}$. It has been suggested that if the storage was in sacks rather than in bins, the need for sloping sides to keep them away from the walls would mean that the centre of the stack would be somewhat higher than this, but this does not affect the basic calculation. In contrast, Gentry $\left(1976,25^{-28}\right)$ in her study of military stone horrea assumed that the grain could be stored to a height of $2 \mathrm{~m}$, although she already pointed out certain problems that prevent us from specifying the exact calculation. Based on this and on the granary's floor area, Gentry proposed in her work (1976, table 2) the capacity in $\mathrm{m}^{3}$ and the theoretical annual grain-holding capacity of different horrea. In the opinion of Sigaut (1981, 168), for a pile about $2 \mathrm{~m}$ wide at its base, it would be impossible to store the grain to a height of more than $1 \mathrm{~m}$. More recent archaeobotanical studies, such as the analysis carried out in the urban warehouse of Amiens (FR), have determined that the average thickness of the cereal layer should be between 20 and $40 \mathrm{~cm}$ (Matterne, Yvinec, and Gemehl 1998; cat. 250) to maintain optimal conservation conditions of the cereal and avoid germination. This proposed height has been accepted by various specialists for calculating the capacity of certain granaries such as the horreum of the villa of Emptinne-Champion at Hamois (BE) (Van Ossel and Defgnée 2001; cat. 05 \& 47), although it is also true that the total amount of grain stored at this height appears small.

From these initial proposals, calculations of capacity proposed by archaeologists have been numerous and varied. Each specialist generally presents a different storage height for the cereal layer or different weights of the grain in each approach. In other cases, minimum capacities have been proposed without taking into account the resistance of the structures to support the weight of the cereal. In two monographs I have already indicated some of the most interesting studies that aim to determine the volume of cereal that could be stored in the horrea, both in military and rural settings (Salido Domínguez $2011,53-55,2017,81-82$ ). I do not intend in this paper to point to more studies that try to justify the published capacity calculations, but only to indicate certain factors that allow us to question some theories and to conclude that these attempts are both inaccurate and incorrect.

The Contribution of Archaeobotanical Analysis to the Study of the Capacity of Roman Granaries

Archaeobotanical analyses are nowadays one of our main sources of knowledge of ancient agriculture, the introduction of new crops, the use and extension of forests, ancient diet, as well as redistribution and long-distance movement of 


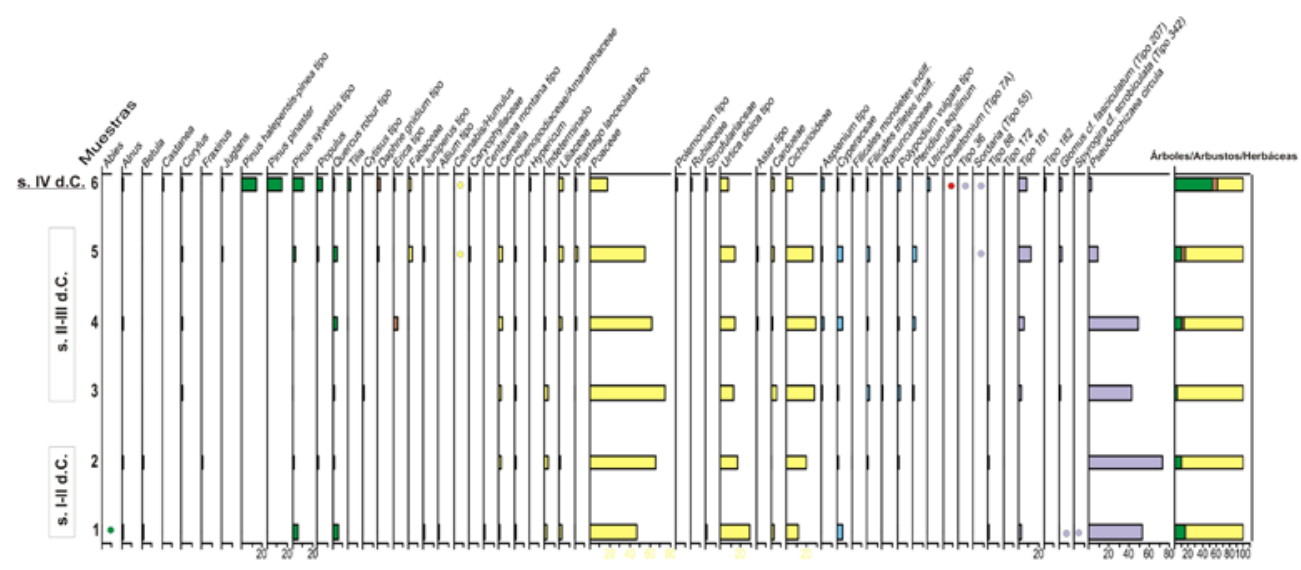

FIGURE 2.1 The palynoligical results on pollen samples from the Roman granary of Veranes (Gijón, Es). Column E5

FERNÁNDEZ OCHOA ET AL. 2012, FIG. 74

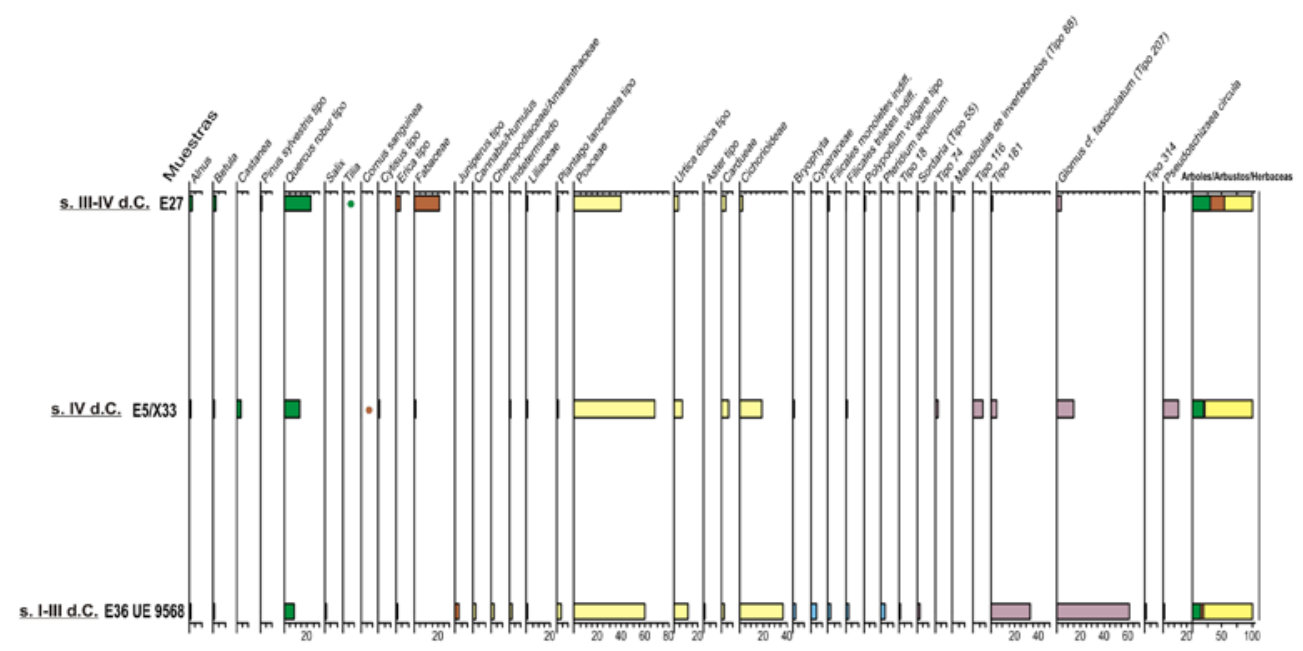

FIGURE 2.2 The palynoligical results on pollen samples from the Roman granary of Veranes (Gijón, ES). Column E27, E36 and room E5 FERNÁNDEZ OCHOA ET AL. 2012, FIG. 74

foodstuffs, and trade in Roman times and, of course, for the study of granaries and their storage capacity. Although ever more effort is being made to approach the production and storage of food from the study of archaeobotanical samples, they are still to be fully integrated into our analysis of the Roman economy. The development of these analyses allows us to interpret as granaries 
certain buildings for which, because of their state of preservation, construction techniques offer little information.

At certain sites, only palynological analysis can give us data about the type of agricultural production and the environment in which the granary is located. This is the case of the horreum of the Roman villa of Veranes (Gijón, Es) (Fernández Ochoa et al. 2012, 161-70). When it was used as a granary in the early Roman Empire, the surrounding landscape was heavily deforested and left practically treeless (Figs. 2.1 and 2.2). Archaeobotanical analyses by J. A. López confirm that there were only deciduous trees, scrub, and bushes in the horreum's surroundings during the early Roman Empire (i.e. English oak/ Quercus robur, alder/Alnus, birch/Betula, ash/Fraxinus, hazel/Corylus, poplar/ Populus, juniper/Juniperus, tree heath/Erica arborea, broom/Cytisus, and walnut tree/Juglans). On the contrary, during the Late Empire, when the horreum became more of a pantry and less of a warehouse, the villa's surroundings were slowly reforested through the recovery of deciduous trees and bushes as well as the repopulation of the forest with various tree species such as the maritime or cluster pine (Pinus pinaster), walnut (Juglans), and chestnut (Castanea). Similarly, this period witnessed a substantial decline in pollen grains (Cerealia) due to progressive reforestation and the lack of agricultural activities in the Veranes surroundings in the fourth century $\mathrm{CE}$. As a result, the research on construction techniques and the archaeobotanical data both confirm a functional change in the original horreum during the late Roman Empire.

The interpretation of the data provided by the palynological analysis together with the macro-remains that give us more information about the study of agricultural practices are still meagre and the conclusions that we can reach are certainly partial. Nevertheless, we will try to approach the archaeobotanical problem in relation to the study of Roman granaries. The main problem that we find is the absence of the application of these analyses to the study of the granaries in some regions, being practically non-existent for the moment in the Mediterranean and very scarce in the case of the British Isles. We also find little detailed information about the stored wheat species or the mode of storage of cereals, without determining if they were kept as spikes, spikelets or grain, or if insects or signs of germination were present.

\subsection{What Species of Grain were Stored in the Roman horrea?}

The cereal species stored in Roman rural granaries were varied. In some horrea such as the granary of Maurepas (FR) (Coulon 1987; Marinval 1993), only naked wheat was found, while in three other granaries, naked wheat was documented together with hulled grain as in the cella penaria of Bliesbruck (FR) where spelt (Triticum spelta) was found (Petit 2005), in the granary of Borg (DE) in 
which barley (Hordeum vulgare vulgare) and emmer wheat (Triticum dicoccum) were recognized (Wiethold 2000) or inside the granary of Parsac "Laschamps" (FR), in which spelt and emmer wheat, as well as oats were documented (Roger and Bet 2005). Naked and hulled wheats were also found together in a number of other granaries, such as the horreum of the Roman villae of Wendens Ambo (Hodder 1982), Bad Dürkheim “Ungstein” (Piening 1988), Bad Rappenau "Babstadt" (Wamser 1977; Wagner-Roser 1987; Herberg 1994, 1998, 1999; Hüssen 2000; Hartmann and Meyer 2001; Hartmann and Reichle 2002), Emptinne-Champion (Van Ossel and Defgnée 2001), Houdan (Philippe 1993; Philippe et al. 1994; Matterne 2001, 155), and Maasbracht (Kooistra 1996, 253-76). When considering the presence of common and durum wheat (Triticum aestivum and durum) in the horrea of Roman villae it should be remembered that they can be used in bread-making, which suggests that the grain preserved in the granaries of Roman rural centres was for local consumption.

\subsection{Not Just Grain: Other Foodstuffs Stored in the horrea}

In some warehouses, different species of wheat and other foodstuffs, such as legumes, were conserved possibly in different storage bins. Legumes were stored increasingly in the Roman era and they could be conserved together with cereals. This is the case of lentils preserved with barley in the granary of Marolles-sur-Seine (FR) (Matterne 2001, 155) or in the horreum from the agglomération secondaire of Crest; in another store building of Crest naked wheat, barley, beans, and fruits were all stored together (Bastard and Stephenson 2002). There is also evidence of other legumes such as peas in Jülich "Kirchberg, WW 112" (DE) (Jenter and Wippern 1997; Päffgen 2000, 283-84; cat. 106), wheat, oats, barley, peas, and beans in Alle ( $\mathrm{CH}$ ) (Othenin-Girard 1999, 2002; Othenin-Girard and Elyaqtine 2002; Demarez et al. 2010; cat. 125 and 221) and Villiers-le-Sec (FR) (Matterne 2001, 155; Wabont, Abert, and Vermeersch 2006, 440-42), and other types of wheat together with peas and beans in Voerendaal (NL) (Willems 1986a, 1987a, 1987b, 1992, 1995; Willems and Kooistra 1987, 1988; Kooistra 1996; Matterne 2001, 158; cat. 33).

The wide range of crops characteristic of the Roman period is also reflected in the archaeobotanical findings of species that must have been introduced or imported, possibly in relation to arboriculture and trade (Willcox 1977). Production of these crops probably boomed in classical times. Fruit species could be transported over great distances using different techniques of preservation, in dried form (figs, grapes, plums) or in amphorae with liquids (olives, peaches). In Biberist ( $\mathrm{CH}$ ), besides barley and spelt wheat, remains of fruits such as plums, cherries, etc. were found (Schucany 2006; cat. 85). Carbonized grapes 
were found in the warehouse of Lournand (FR) (Devauges 1979, 457-58; cat. $132)$.

\subsection{How was the Grain Stored?}

During the storage period, it was necessary to air the grain properly, regularly inspect the stocks, and clean the grain stored in order to keep the cereal dry at a uniform temperature and protected from insects, rodents, and other pests (Fig. 2.3). These requirements were of great importance to ensure safe storage. In raised granaries, the commonest way to store grain was to pour it in bulk or in spikes directly onto the floor, whether they were naked or hulled cereals. Archaeological data show that cereals were stored in bulk in the military stone granaries of South Shields (van der Veen 1988), Valkenburg (Pals, Beemster, and Noordam 1989), as well as in the urban areas of Alcester (Booth 1989), London (Straker 1984), Amiens "ZAC Cathédrale" and in the granary of the roman villa of Voerendaal (Kooistra 1996). Classical sources mention the construction of spaces or bins to separate the different types of grains (Col. 1.6.9-24) and the study of the archaeobotanical remains found inside the horreum of Amiens "ZAC Cathédrale" confirms some internal organization and separation of products in the storage chamber (Matterne, Yvinec, and Gemehl 1998).

Conservation of the grain in spikelets improved the protection against the risks associated with humidity, often responsible for early germination or insect damage. Grain husks also ensured the cereals remained clean throughout the storage period. To that end, Pliny (Nat. 18.73) recommends storing grain in spikes. They were mostly stored with glumes in the granary of Houdan (FR). Although few analyses have been made, it is possible to determine that hulled grains were often stored in spikes or spikelets after initial sieving or threshing. In contrast, naked grain was usually stored clean in Roman rural centres.

In point of fact, despite the advantages of storing the cereal in spikelets that better isolates the grain from moisture and reduces the risks of germination, it was also stored completely clean in Roman times. The fact that grain was stored dehusked could indicate that it was to be consumed on the spot. This could in turn indicate a high degree of self-consumption, meaning that grain would have been consumed where it was produced. This was the case of the granary of the Roman villa of Wendens Ambo, where a grain dryer contained common, spelt, and emmer wheat (Triticum aestivum, spelta, and diccocum).

Some studies have documented the weeds found with the grain inside the warehouses. In the granary of the Roman villa of Champion, bromine (Bromus sp.), cleavers (Galium aparine), Polygonum Convolvulus, pale persicaria (Polygonum lapathifolium), Chenopodium album, Plantago lanceolata, and Rumex acetosella are found. Also interesting is the presence of alfalfa (or lucerne, 


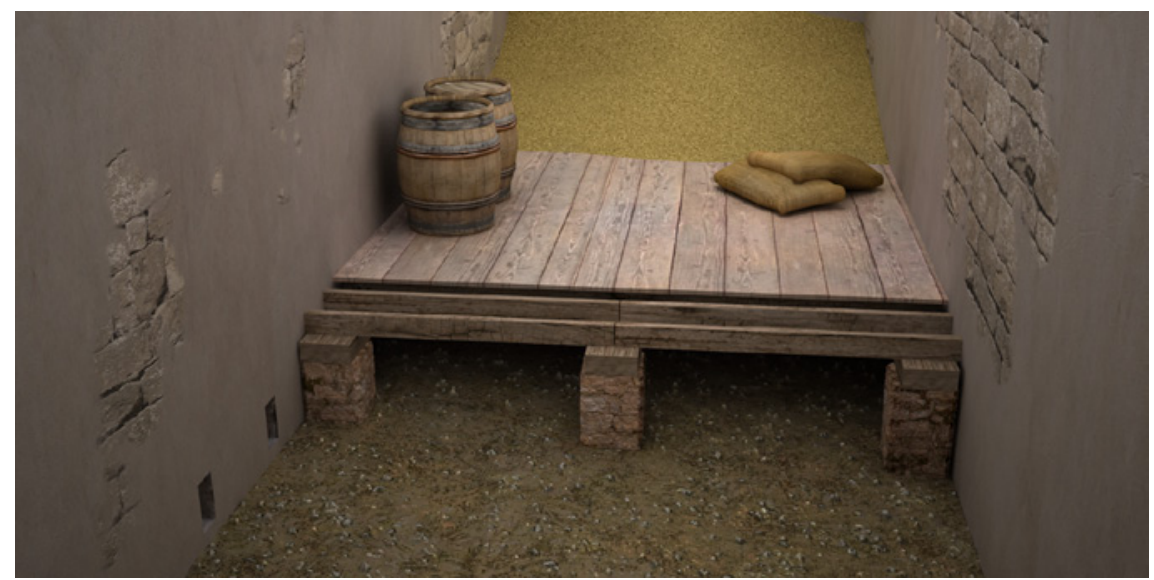

FIGURE 2.3 Reconstruction of the tabulatum and supports of the granary of Veranes (Gijón, Es)

FERNÁNDEZ OCHOA ET AL. 2012, FIG. 57

Medicago sativa) and cultivated pea (Vicia sativa) that were grown as fodder (Van Ossel and Defgnée 2001). Medicago lupulina and wild radish (Raphanus raphanistrum) were also detected among the different types of wheat found in the granary of Maasbracht. In the horreum of Voerendaal, the grain was threshed and cleaned before being stored, but there was a high proportion of weeds and straw with common corn-cockle (Agrostemma githago), rye brome (Bromus secalinus), and Venus' comb (Scandix Pecten-veneris) being predominant. The grains of common windgrass (Apera spica-venti) and the seeds of poppy (Papaver dubium/p. Rhoeas) attested in this granary were also remains of threshing.

\subsection{The Consequences of Poor Environmental Conditions or Prolonged Storage: Insects}

Grain was exposed to a number of pest insects that could cause a major decline in cereal quality. The problems of germination of stored grain increased considerably in Roman times with the construction of huge store buildings while the conservation of large volumes of grain for extended periods for market distribution and long-distance transport posed major problems and entailed losses. Germination might either be controlled for malting and brewing or be accidental, caused by adverse environmental conditions with excessive relative humidity $(20-25 \%$ or more). Controlled germination has been found in the granary of Bliesbruck where spelt wheat was documented still wrapped 
in its glumes. It was beginning to germinate at the time of its carbonization, suggesting that it was used for the production of beer (Petit 2005). It is important to remember that the conservation of hulled rather than dehusked grain increased protection against a damp environment, which was often responsible for early germination or degradation by insects. As in Amiens "ZAC Cathédrale", much of the wheat found in a cellar of Mont Beuvray (FR) was also burned when it had germinated (Barral, Beck, and Bonenfant 1993; Barral et al. 1995). It is probable that germination was due not only to the conservation conditions, but also to the duration of storage.

We do not know how long the cereal was kept in the granary. If we consider the textual information, Ausonius boasts about storing harvests for two years in his villa (Hered. 27). On the basis of this information, it would be useful to ask whether the granaries served for storage of all or part of the harvest. If they could contain all the reserves collected, the study of their capacity would even allow us to determine the area of land suitable for cultivation. Thus, we could estimate the hectares of the fundus taking into account the areas reserved for livestock, the forest mass, and the area under cultivation. In this regard, I believe there are some data that allow us to question this theory and to argue that many granaries did not conserve all the crop. Most of it was probably marketed and not stored in the rural granaries (Cato, Agr. 2.7). The Digest indicates that the preserved provisions were "more available for maintenance than for cultivation" (Dig. 33.7.12), so the cereal harvested seemed to be intended for these two purposes. On the other hand, we should take into account that the interest of the dominus lay in selling agricultural surpluses, rather than accumulating products, because these could be lost due to various factors (humidity, temperature, insects, rodents, etc.). It should also be borne in mind that damage caused by long-term storage might not only result in the loss of the cereal, but also adversely affect the quality and the nutritive value of the product. In this market logic, it seems more convenient to send the harvest for sale in the urban areas (Salido Domínguez 2013; Salido Domínguez and Bustamante Álvarez 2014). This would explain why most of the granaries were of medium dimensions, up to $10 \mathrm{~m}$ long and $5 \mathrm{~m}$ wide (Salido Domínguez 2017, 88). In conclusion, most of the harvest was not intended for storage, but for sale and, in consequence, the stored cereal should not be taken as representative of the agricultural capacity of a Roman rural centre. In a military context, Tacitus (Agr., 12.2) indicates that the granaries had enough capacity for one year. However, it was in the Roman army's interest to store it and so have grain for the winter (6 months). According to Gentry's calculations, with a storage height of $2 \mathrm{~m}$, there was enough space to store grain for at least two years if not more. Since there 
is no doubt that these calculations are incorrect, these proposals should be challenged.

\section{$4 \quad$ Quantitative Scepticism}

Several factors enable us to question the proposed quantification of Roman granaries' storage capacity, which lead to what we call the "Quantitative Scepticism":

1. We do not know what type of cereal was stored in most of the granaries (see section 3.1). This information is essential, since the weight of each species of cereal is different (Gentry 1976, 25).

2. Not only grain but other products were preserved in the horrea as made clear by archaeobotanical analysis (see section 3.2).

3. We generally do not know the mode of storage: in bulk, in sacks, or in bins and if it was kept in spikes or cleaned (see section 3.3).

4. A theoretical calculation can be proposed for a full granary, but these were continuously emptied at each harvest according to the needs of their owners. A horreum will never be able to provide us with an estimate of the agricultural potential of a rural centre, since most of the harvest was destined for sale, redistribution, and almost immediate commercialization. The owner of a rural establishment was not economically interested in keeping a product as perishable as grain (see section 3.4).

5. Archaeobotanical analyses indicate that not all the surface of the floors would be covered by grain, because it was necessary to leave free space for circulation and ventilation to prevent the grain from germinating. In addition it is very possible that there were different compartments in the interior to separate the types of grain (see section 3.3).

6. It is necessary to calculate the load-bearing capacity of the tabulatum or floor of the granary, which is hard to do unless we know the construction material. Most of the granaries were made of wood, but the floor strength also depends on the species of wood.

7. The research experts do not agree about the right height of the pile of grain to ensure it did not spoil (see section 2). Undoubtedly, the height of the pile would depend on the time of storage and the possibility of accessing the different parts of the storage chamber to remove the grain and thus prevent germination or infestation of the lower part of the heap where higher temperatures reigned. 
8. We do not know how long grain was kept in the granary. If we consider the textual and archaeological information, we can conclude that the stored cereal was not representative of the agricultural capacity of a Roman rural centre which would not necessarily keep the grain for a year (see section 3.4).

\section{Conclusion}

Information from archaeobotany and ethnoarchaeology warns us of the need to review the studies of quantification of the maximum grain capacity stored in Roman horrea, to reconsider the data referring to the agricultural exploitation of a territory, as well as to the quantity of cereal estimated for direct consumption and export. In short, we propose to question or relativize the proposed capacity, until multidisciplinary studies combining the physical principles of the load-bearing capacity of the tabulata and of the preservation of the grain allow us to address this problem in the most appropriate way possible.

In my view there is no need to publish further quantification models of the capacities of Roman granaries. Therefore, I advocate taking into account the qualitative rather than the quantitative aspects of the storage in horrea to compare and contrast the capacities of the different granaries. In this way, comparison of the volumes of the different horrea in order to classify the buildings according to their storage capacity could help determine the centres of production, intake and provisioning and allow us to reach conclusions about the procedures for collecting and shipping grain, and the commercial networks and techniques for supplying grain in Roman times. We hope that physical studies, with the help of new technologies, will enable us to solve in part this archaeological problem in the near future. 